Please do not remove this page

RMIT

UNIVERSITY

\title{
Understanding collaborative search for places of interest
}

Aldosari, Misfer; Sanderson, Mark; Tam, Audrey; Uitdenbogerd, Alexandra

https://researchrepository.rmit.edu.au/esploro/outputs/9921859288501341/filesAndLinks?institution=61RMIT_INST\&index=null

Aldosari, M., Sanderson, M., Tam, A., \& Uitdenbogerd, A. (2016). Understanding collaborative search for places of interest. Journal of the Association for Information Science and Technology, 67(6), 1331-1344. https://doi.org/10.1002/asi.23466

Document Version: Accepted Manuscript

Published Version: https://doi.org/10.1002/asi.23466

Repository homepage: https://researchrepository.rmit.edu.au

(c) 2015 ASIS\&T

Downloaded On 2023/04/26 20:54:38 +1000

Please do not remove this page 
Thank you for downloading this document from the RMIT Research Repository.

The RMIT Research Repository is an open access database showcasing the research outputs of RMIT University researchers.

RMIT Research Repository: http://researchbank.rmit.edu.aul

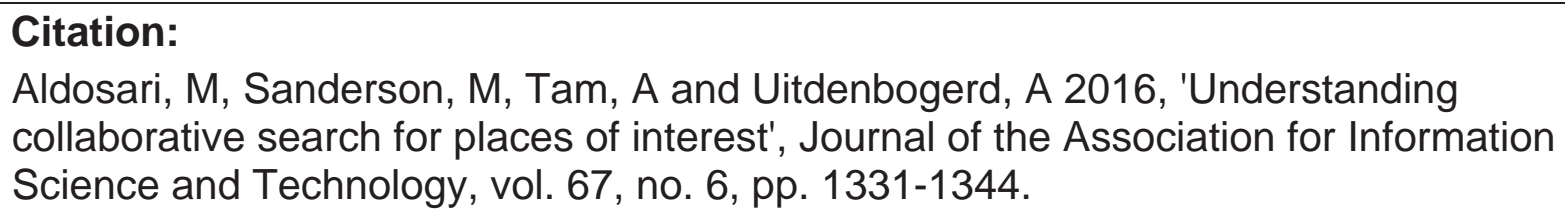

See this record in the RMIT Research Repository at:

https://researchbank.rmit.edu.au/view/rmit:35943

Version: Accepted Manuscript

Copyright Statement:

(C) 2015 ASIS\&T

Link to Published Version:

https://dx.doi.org/10.1002/asi.23466 


\title{
Understanding Collaborative Search for Places of Interest
}

\author{
Misfer Aldosari \\ RMIT University \\ Melbourne, Australia \\ s3274205@student.rmit.edu.au
}

(Corresponding author)

Mark Sanderson

RMIT University

Melbourne, Australia

mark.sanderson@rmit.edu.au

Audrey Tam

RMIT University

Melbourne, Australia

audrey.tam@rmit.edu.au

Alexandra L. Uitdenbogerd

RMIT University

Melbourne, Australia

alexandra.uitdenbogerd@ @mit.edu.au 


\section{ABSTRACT}

Finding a place of interest (e.g. a restaurant, hotel, or attraction) is often related to a group information need, however, the actual multi-party collaboration in such searches has not been explored, and little is known about its significance and related practices. We surveyed 100 computer science students and found that $94 \%$ (of respondents) searched for places online; $87 \%$ had done so as part of a group. Search for place by multiple active participants was experienced by $78 \%$, with group sizes typically being two or three. Search occurred in a range of settings with both desktop PCs and mobile devices. Difficulties were reported with coordinating tasks, sharing results and making decisions. The results show that finding a place of interest is a quite different group based search than other multi-party information seeking activities. The results suggest that local search systems, their interfaces and the devices that access them can be made more usable for collaborative search if they include support for coordination, sharing of results, and decision making.

\section{INTRODUCTION}

Local geographical search is an important part of the Web search landscape, as people increasingly look for information about places of interest, such as restaurants, hotels and attractions. Gan, Attenberg, Markowetz, and Suel (2008) found that $13 \%$ of all queries submitted to a standard search engine were geographically focused. In addition to standard search engines, people often use local search, that is, search for items that exist in a specific geographic location, to find places of interest, as well as social services with a geographical dimension, such as Foursquare and Google+Local.

Finding local information is an important element of mobile search. It was determined that the search for location-based information represented about 9-10\% of a 2007 two-month query collection of Yahoo! mobile search (Yi, Maghoul, \& Pedersen, 2008), and more than $15 \%$ of a sample containing over one million queries submitted through Google mobile search in 2006 (Kamvar \& Baluja, 2006). Search for places of interest was the third most popular information need in mobile search, as found by Sohn, $\mathrm{Li}$, Griswold, and Hollan (2008). In recent years, mobile Web usage has grown: according to Google, mobile searches in the US have quadrupled in about one year (2010/2011); and one in three mobile searches are local (Spero, 2011).

Location-based information needs can be related to groups; for example, friends may want to look for a restaurant to dine in together; or family members may look for a holiday house. Amin, Townsend, Ossenbruggen, and Hardman (2009) studying mobile information needs, reported that most local searches (around 75\%) were issued while being with others; some of which were group information needs. Another recent study found that $63 \%$ of location-based queries were issued in a social context and were discussed with someone else (Teevan, Karlson, Amini, Brush, \& Krumm, 2011).

Poltrock et al. (2003) defined collaborative information retrieval (IR) as "the activities that a group or team of people undertake to identify and resolve a shared information need". Traditional activities of IR involve identifying a need for information, formulating a query, performing the retrieval, examining the results, and probably extracting information from them. In addition to these activities, collaborative IR also includes, according to Poltrock et al. (2003), communicating about the information need, sharing 
retrieval results with group members, and coordinating the search task between the participants. As will be seen later, we used a somewhat more restrictive form of Poltrock's definition.

While these findings suggested a strong association between local search and group/social activities, little is known about such activities. While collaboration in general Web search has been studied (Capra, Velasco-Martin, \& Sams, 2011; M. R. Morris, 2008), collaborative local search is both unstudied and appears to be different from the types of collaboration studied so far. Collaboration in general web search is often undertaken in order to find a large number of difficult to locate items. Often collaboration is used as a means to achieve as close to $100 \%$ recall as possible. By contrast, in local search, the aim is often to find a single item, the place of interest. It would be reasonable to expect that part of the process of selecting an item will include a discussion between collaborators on which place of interest they will select. In general collaborative search, the discussion might be about whether an item fits a common view of relevance. In local search, however, the discussion will be more focused on whether the place of interest is a good compromise between the competing preferences and constraints of the collaborators.

Thus, we aim through this study to gain insight into the collaborative search activities that might happen when a group of people search for a place of interest. More specifically, the research questions that this study addresses are:

- How often do group-based searches for places of interest occur? In how many of these searches is there actual collaboration among some or all of the group?

- What are the details of the collaboration? What are the common targeted places of interest, how are mobile devices used, who is controlling the search, what size of group is involved, are the group members co-located or remote, and how does the collaboration takes place?

- What, if any, are the obstacles faced during the collaboration?

- How important is the process of deciding which place of interest will be chosen? And how is that decision made?

In the next section of this paper we report on previous studies related to search collaboration and locationbased information needs, followed by an explanation of our methodology. We then present the results of the study and contrast them with previous related findings. This is followed by a discussion of how the findings might be used to make local search systems and interfaces more usable for collaborative search, and our conclusions.

\section{RELATED WORK}

It has been pointed out that search can be a collaborative and social process, e.g. (Large, Beheshti, \& Rahman, 2002; Talja, 2002; Twidale, Nichols, \& Paice, 1997). Twidale et al. (1997) conducted an observational study of collaboration activities on computer terminals in a university library. Much collaboration was observed, and several types of interactions were identified: groups of students gathered around a terminal to discuss and perform their group-based information task; alternatively, collaborators worked on separate terminals while discussing their actions and comparing results. 
More recent research confirmed the importance of collaboration (Amershi \& Morris, 2008; Capra et al., 2011; Evans \& Chi, 2008; Morris, 2008). Over half of the 204 employees of a large technology company surveyed by Morris (2008) indicated that they had cooperated with others to perform many search tasks. Nearly all reported engaging in one or more of a given set of activities associated with search collaboration, such as sharing search results through email, and looking over someone's shoulder to help in the search. Capra et al. (2011) investigated search collaboration by recruiting participants from Amazon Mechanical Turk to respond to a survey about Web search behavior. A number of collaboration scenarios were revealed. Single session, synchronous, co-located, cooperative search was found to be the most common, followed by multiple session, mixed concurrency (synchronous and asynchronous), and mixed presence (co-located and remote) collaboration.

Interviews with three teachers and two librarians by Amershi \& Morris (2008) indicated that sharing a single computer to perform a co-located collaborative Web search is a common practice in schools and libraries to complete various search tasks. Such search was also found to be a common activity both at work (55.3\%) and home (44.7\%) (Amershi \& Morris, 2009). The authors showed that communication becomes less effective between group members with different personalities or levels of search expertise; for instance, the member controlling the computer may ignore suggestions by the others.

A survey by Evans \& Chi (2008) looked at social aspects of collaborative search through a survey of 150 users from a crowd sourcing system. Social interactions with others, whether or not they are directly related to the information need, were found to play a key role throughout the search process. For over a third of the studied sample, such interactions occurred both before and after their most recent Web searching behavior, and occurred at some point during the search process for two thirds.

Toze, Peet, and Toms (2011) conducted a lab experiment of collaborative search. Two groups of students cooperatively worked on real-world course-assigned group-based projects. Toze et al. reported that active collaboration between two or more group members occurred primarily before and after the search, i.e. during the information need generation, and the information extraction from found results. However, the actual finding activity was mostly performed by a single group member, and rarely by a pair.

In a study of exploratory search, Capra, Marchionini, Velasco-Martin, and Muller (2010) interviewed thirty participants from three different groups of people (academic researchers, corporate workers, and people looking for medical information). Various methods for communication and information sharing were reported: email (80\%), face-to-face (67\%), telephone/conference calls (37\%), printouts (37\%), blogs/webpages (17\%), shared network hard drives (13\%), and instant messaging (10\%). In terms of how the collaboration was performed, they identified three styles: directed collaboration (one person is leader, others conducting the searches), tightly coordinated collaboration (search task divided into parts among group members), and loose/informal collaboration (searches conducted and results shared in an ad-hoc manner).

It has been pointed out that mobile search is often conducted alongside others, for example family members and friends (Church \& Oliver, 2011). Conversations have also been found to have a significant impact on information needs arising in mobile settings (Church \& Smyth, 2009; Sohn et al., 2008). Church, Cousin, and Oliver (2012) revealed information about behaviors of social mobile search (defined as the "use of mobile search in co-located group settings to satisfy a shared information need"). For example, in most cases users share results verbally, and rarely hand over the mobile device or send the 
results electronically. Finding fact about a certain topic (e.g. wanting to settle a friendly bet while chatting with a friend), and looking for assistance with an activity or task (e.g. finding directions) were the main motives for such social mobile search.

Focusing on mobile local search behavior, Amin et al. (2009) conducted a diary study and Teevan et al. (2011) surveyed participants to report on their most recent search. Both studies showed contextual factors: spatial, temporal, and social. The active collaboration on local search by more than one person has not been fully explored and little is known about its frequency, characteristics, methods, and problems.

Collaborative search is often conducted to solve complex information seeking tasks that in many cases require finding potentially large numbers of relevant documents. Examples of such tasks described in the literature include students working on a group project or assignment (Saleh \& Large, 2011; Toze et al., 2011), people seeking medical information for themselves or a family member (Capra et al., 2010; M. R. Morris \& Horvitz, 2007), and professionals working on a group task (Capra et al., 2010; M. R. M. Morris, 2013), such as preparing a newspaper report (Capra et al., 2012; González-ibáñez, 2011; Shah, 2013), and handling of patent applications (Hansen \& Järvelin, 2005).

A class of interactive computer systems known as group decision support systems (GDSS) have long been used to help multiple people, jointly responsible for making decisions, reach consensus (DeSanctis \& Gallupe, 1984; Power, 2004). However, such systems are usually designed for solving complex organizational decisions. Less research has been conducted on more informal decisions, such as making the choice of which place of interest to pick.

Different aspects of collaboration on Web search have previously been investigated. However, in addition to being linked to group activities, finding local information is a type of Web search that has gained interest, and many Web sites and mobile applications were created specifically for local search tasks. Hence, the primary contribution of this paper is an investigation of collaborative behavior associated with local search for places of interest on mobile or non-mobile devices, including the prevalence of multiparty participation, collaboration settings, how it occurs, the difficulties that might be associated with it, and the group-based decision making process.

\section{METHODOLOGY AND DATA}

We developed a survey questionnaire (Kasunic, 2005) to investigate collaboration practices in the search for places of interest. Surveys, if well-designed and tested, can provide an effective way to study how individuals interact with technologies and what problems they face, especially in the case where it might be hard to obtain such information from existing computer data, i.e. logs (Lazar, Feng, \& Hochheiser, 2010). Surveys have been used to study collaboration behaviors in Web search and behaviors related to carrying out mobile search, e.g. (Amershi \& Morris, 2009; Capra et al., 2011; Evans \& Chi, 2008; Morris, 2008; Teevan et al., 2011). The survey design was inspired by the work of Morris (2008).

In the questionnaire a place of interest was defined as: "any place associated with a specific geographical location that someone might find useful or interesting to go to. Examples are: restaurants, hotels, shops, entertainment attractions, natural attractions, etc". The questionnaire had three main parts: 
1. Demographics, smartphone ownership, and local Web search practices;

2. The nature of collaboration during search; and

3. How the group decided which of the places of interest the group they would choose to go to.

Apart from four free-form answers, all questions were multiple-choice, some were conditional on answers given earlier. The questionnaire was developed through three pilot tests where three to four graduate students at RMIT University completed the questionnaire in the presence of one of the researchers. The participants were instructed to report any ambiguity or difficulty in understanding or answering any part of the questionnaire. The feedback was used improve the wording and structure of the survey.

The questionnaire was delivered using the Qualtrics ${ }^{1}$ online tool. An invitation (sent in June 2012) to take part was distributed via email to computer science and information technology students; participation was voluntary. The demographic of computer science and information technology students was chosen as it was assumed the participants would be early adopters of smartphones and experienced in their use. The survey was anonymous, therefore, no follow up contact with participants was possible.

One hundred students participated, of whom 28 did not fully complete it. When analyzing the results, we considered all the answers to each question; the number of answers is mentioned when reporting the results and percentages are calculated in relation to that number, unless otherwise stated. A table listing the questions and number of respondents is in Appendix A.

\subsection{STUDY LIMITATIONS}

The reader should be reminded about two main limitations of this methodology:

- As the cohort used in the questionnaire was selected to include participants who are expected to be early adopters, the generalization of the results to the wider population will not occur until web and mobile technologies become more widely adopted.

- Despite their effectiveness at capturing users practices, surveys gather retrospective self-reported data that may contain inaccuracies, including recall, and perceptual biases (Metts, Sprecher, Cupach, Montgomery, \& Duck, 1991).

\section{RESULTS}

The survey started with four general questions. First, gender was determined: $72 \%$ of the 100 respondents were male, and $28 \%$ were female (82\% of our target group was male). Second, participant age was requested: the dominant group was 21-29 (58\% of survey participants), followed by 18-20 (21\%), 30-39 (13\%), and 40-49 (6\%). Two participants were 50 or older. Third, highest educational level was determined. A bachelor's degree and high school degree or equivalent were the highest degrees for $27 \%$ and $26 \%$ of participants respectively; three participants had not completed a high school degree; $16 \%$ of the respondents had some college but no degree, $6 \%$ had an Associate degree, and $16 \%$ had a graduate

\footnotetext{
${ }^{1}$ http://www.qualtrics.com/
} 
degree. A high percentage of the participants were graduate students (43\%), despite representing only $22 \%$ of the target group emailed about the survey. We speculate that this is due to their engagement in research, and therefore greater interest in taking part in such studies.

\begin{tabular}{|l|r|}
\hline Age & Percentage \\
\hline $18-20$ & $21 \%$ \\
\hline $21-29$ & $58 \%$ \\
\hline $30-39$ & $13 \%$ \\
\hline $40-49$ & $6 \%$ \\
\hline 50 or older & $2 \%$ \\
\hline
\end{tabular}

Table 1. Age groups of the respondents

\begin{tabular}{|l|r|}
\hline Degree & Percentage \\
\hline $\begin{array}{l}\text { Less than high school } \\
\text { degree }\end{array}$ & $3 \%$ \\
\hline $\begin{array}{l}\text { High school degree or } \\
\text { equivalent }\end{array}$ & $26 \%$ \\
\hline $\begin{array}{l}\text { Some college but no } \\
\text { degree }\end{array}$ & $16 \%$ \\
\hline Associate degree & $6 \%$ \\
\hline Bachelor degree & $27 \%$ \\
\hline Graduate degree & $22 \%$ \\
\hline
\end{tabular}

Table 2. The education level of the respondents

Use of location-based services is strongly associated with smartphone use ${ }^{2}$. Thus, fourth we asked "Do you use a smart-phone (ex. an iPhone, Android, or Windows mobile device)?". The majority, 81\%, answered "yes", 19\% "no" (100 answered).

\footnotetext{
${ }^{2}$ According to the Pew Research Center's Internet \& American Life Project, as of February 2012, about threequarters $(74 \%)$ of smartphone owners in the U.S. use location-based information services.
} 


\subsection{Finding Places of Interest}

We next tested the prevalence of using the Web to find a place of interest by asking: "How often did you use the Web to find a suitable place of interest (a restaurant, hotel, shop, entertainment attraction, natural attraction, etc.)? (Through a mobile or non-mobile device)". The responses (98) and their percentages are presented in Table 3.

\begin{tabular}{|l|r|}
\hline Response & Percentage \\
\hline Daily & $10 \%$ \\
\hline 2-3 Times a Week & $19 \%$ \\
\hline Once a Week & $16 \%$ \\
\hline 2-3 Times a Month & $31 \%$ \\
\hline One a Month & $12 \%$ \\
\hline Less than Once a Month & $5 \%$ \\
\hline Never & $6 \%$ \\
\hline
\end{tabular}

Table 3. Frequencies of using the Web to find a place of interest (percentages may not sum to total due rounding).

In order to find out how many such searches were conducted on mobile phones, we asked: "Thinking of these occasions when you used the Web to find a place of interest, how many of these occasions was a mobile device used in the search/browse?". This question was only visible to those who had used the Web to find a place of interest (i.e. not selected "Never" in the previous question). As the results presented in Table 4 suggest, searches for places of interest were not dominated by the use of mobile devices.

\begin{tabular}{|l|r|}
\hline Response & Percentage \\
\hline All & $7 \%$ \\
\hline Most & $27 \%$ \\
\hline About Half & $19 \%$ \\
\hline Few & $30 \%$ \\
\hline None & $17 \%$ \\
\hline
\end{tabular}

Table 4. The amount of searches for places of interest carried out through a mobile device.

\subsection{Group-Based Finding of Places of Interest}

To understand the situations where a group of people could potentially cooperate on finding a place of interest, we asked: "How often were you part of a group (two or more people) in which the Web was used 
to find a suitable place of interest for the group? (Whether the search was done by yourself or/and others in the group, through a mobile or non- mobile device)". The results (Table 5) showed that the majority $(87 \%)$ of respondents $(n=95)$ were involved in such a situation at least once. Moreover, we found that these situations appeared to be taking place quite frequently. Nearly half $(47 \%)$ of the respondents were involved in such a situation at least two to three times a month.

\begin{tabular}{|l|r|}
\hline Response & Percentage \\
\hline Daily & $2 \%$ \\
\hline $2-3$ Times a Week & $6 \%$ \\
\hline Once a Week & $14 \%$ \\
\hline 2-3 Times a Month & $25 \%$ \\
\hline Once a Month & $15 \%$ \\
\hline Less Than Once a Month & $25 \%$ \\
\hline Never & $13 \%$ \\
\hline
\end{tabular}

Table 5. Frequencies of being part of a group that used the Web to find a place of interest.

We ran a Mann-Whitney U test to evaluate the difference in the reported frequency of group-based search for places of interest (on the ordinal scale from "Never" to "Daily") between the demographic groups in our sample. The results suggested that female participants have a significantly higher frequency of group search involvement (mean rank $=57.5$ ) than male ( mean rank $=44.9), U=1180, z=-2.02, p=0.0434$. Additionally, smartphone users were involved in group-based search for places of interest more frequently than non-smartphone users (with mean ranks of 51.2 and 37.6, respectively), $U=523.5, z=$ $1.91, p=0.0561$. No significant difference was found between graduate and undergraduate students, $U=$ $1058, z=0.17, p=0.865$; the mean ranks for the two groups were close: 47.5 and 46.5 , respectively.

A Kruskal-Wallis test was run to determine if there were differences in the frequency of group search between the age groups. The frequency was higher among the people in the 21-29 age group (mean rank $=53.3$ ), followed by 30-39 (mean rank $=44.7)$, 40 or older (mean rank 39.5), and 18-20 (mean rank = 38.4), but the differences were not statistically significant, $\chi^{2}(3)=5.33, p=0.1492$.

\subsection{Collaboration on finding places of interest}

We next asked: "Thinking of these occasions when the Web was used to find a place of interest for the group, how many of these occasions did more than one member of the group participate (by any form) in the search/browse?". As the participation on the search can occur in various degrees, the following description was provided to make clear what we mean by the participation: "(Whether the participation was by actually doing a search/browse on a mobile/non-mobile device, or by trying to help someone in the group who is doing that)". This explanation results in a stricter meaning for collaboration than Poltrock et al. (2003), as it excludes identifying the information need. The majority (90\%) of the 
respondents to this question $(\mathrm{n}=82)$ reported that there was collaboration by more than one member of the group in at least one of these occasions. That represents $78 \%$ of the survey respondent population ${ }^{3}$.

\begin{tabular}{|l|r|}
\hline Response & Percentage \\
\hline All & $1 \%$ \\
\hline Most & $21 \%$ \\
\hline About Half & $27 \%$ \\
\hline Few & $41 \%$ \\
\hline None & $10 \%$ \\
\hline
\end{tabular}

Table 6. The proportion of group-based searches for places of interest that involved multi-person participation.

Although we found a significant difference in the frequency of group-based search for places of interest with regard to gender and age, no such difference was found between the various demographic groups when it came to the frequency of the actual collaboration among group members.

We next asked about the setting for the collaboration and how the participation occurred. In order to make the context of these questions clear to the respondents, the following statement was displayed before the questions: "Thinking of these occasions when more than one member of the group participated in the Web search/browse for a place of interest, please answer the following questions".

\begin{tabular}{|l|r|}
\hline Response & Percentage \\
\hline Places to eat or drink & $88 \%$ \\
\hline Places to shop & $33 \%$ \\
\hline Places to stay (hotels, holiday houses, etc.) & $23 \%$ \\
\hline Entertainment attractions (cinema, music venues, etc.) & $59 \%$ \\
\hline Nature \& wildlife attractions (parks, gardens, etc.) & $19 \%$ \\
\hline Art \& culture attractions (museums, art galleries, etc.) & $14 \%$ \\
\hline Other & $3 \%$ \\
\hline
\end{tabular}

Table 7. Targeted places of interest.

\footnotetext{
${ }^{3}$ Considering the 95 who answered the previous question, as the current question was only displayed to a subgroup of participants who had the experience of group-based local search.
} 


\subsubsection{Targeted places of interest}

First we asked "In these occasions, what were the most common (up to 3) targeted places of interest?". We provided a number of categories to multiply select from, as well as an "Other" choice with an associated text box. The most popular category was places to eat or drink ( $88 \%$ of the 69 respondents), followed by entertainment attractions (59\%), and places to shop (33\%) - see Table 7.

\subsubsection{Attributes of collaborative search}

As in (Capra et al., 2011; M. R. Morris, 2008), we asked about the location of the participants when collaborating on the search: "How often of these occasions were group members together (face-to-face) when participating on the search/browse for a place of interest?". Being face-to-face with other group members was more frequent than being apart: $35 \%(n=69)$ of respondents reported being together in most of their collaborative local searches, and $16 \%$ were together in all of them (Table 8).

\begin{tabular}{|l|r|r|r|r|r|}
\hline Response & All & Most & About half & Few & None \\
\hline Face-to-face & $16 \%$ & $35 \%$ & $25 \%$ & $20 \%$ & $4 \%$ \\
\hline At least one mobile device used & $7 \%$ & $48 \%$ & $22 \%$ & $17 \%$ & $6 \%$ \\
\hline Using multiple mobile devices while face-to face & $2 \%$ & $34 \%$ & $23 \%$ & $34 \%$ & $6 \%$ \\
\hline The search is operated by one member & $7 \%$ & $32 \%$ & $30 \%$ & $29 \%$ & $1 \%$ \\
\hline
\end{tabular}

Table 8: The rate of occurrence of different settings for collaborative search for places of interest (percentages may not sum to total due rounding).

Determining the popularity of mobile devices used in cooperative search, we asked: "How often of these occasions was at least one mobile device used to find a place of interest for the group?". Although mobile devices were found not to dominate in the search for places of interest (as previously reported), it can be seen from Table 8, row 2, at least one mobile device was used in most searches (48\%), while only $6 \%$ never used a mobile device in collaborative search.

In the work by Teevan et al. (2011), several respondents reported that more than one person searched on a mobile device when looking for location-based information; however, there was, apparently, no direct inquiry about this situation. So, in a sub-question we asked: "Thinking of these occasions when the group members were together (face-to-face) when participating on finding a place of interest, how many of these occasions did two or more group members use their mobile devices to participate on the search/browse"? This question was only relevant to those who at least once were co-located, used a mobile device, and the actual search was operated by more than one individual $(n=47)$.

One third of the respondents (Table 8, row 3) reported the use of multiple mobile devices in most of their co-located collaborations, and 23\% answered "About half", while only three participants reported that they had never experienced such collaboration.

\footnotetext{
${ }^{4}$ Note that the percentages for this setting are related to face-to-face collaboration cases.
} 
In the question about the prevalence of collaborative search (Table 6), the collaboration could take any form. Now, we asked about the nature of the collaboration: "How often of these occasions was the actual search/browse for a place of interest done by only one group member, while some or all of other group members participated by trying to help him/her on the search/browse?". Searches operated by just one person (Table 6, row 4), were common $(n=69)$. However, because the low number of times respondents answered "All", by implication most respondents have experienced collaborative search.

To determine the typical size of groups of collaborators, we asked "Typically, how many group members participated on the search/browse for places of interest?" $(\mathrm{n}=69)$. In our results, two person collaborations appeared to be less commonplace (45\%) than indicated in past work, but were still the most common group size reported. Collaborative search involving three people (37\%) was more common than results reported elsewhere. Five or more collaborators represented $8 \%$ in our survey with only one response reporting more than five.

Table 9. Number of people participating in the search.

\begin{tabular}{|c|r|r|r|r|}
\hline Typical Group Size & 2 & 3 & 4 & $\geq 5$ \\
\hline Proportion of Responses & $45 \%$ & $37 \%$ & $9 \%$ & $8 \%$ \\
\hline
\end{tabular}

\subsubsection{Experiences of collaborative searches operated by more than one person}

Respondents who reported the experience of two or more people using their mobile/non-mobile devices to search were asked an optional free-form question: "Thinking of the occasions when two or more group members used their mobile/non-mobile devices to participate on finding places of interest, please describe how the collaboration occurred. (Ex. in terms of dividing/coordinating tasks, sharing results, etc.)". Answers (29) showed that the majority of local cooperative searches occurred in an ad-hoc basis without being explicitly coordinated between the group members (79\%). Every collaborator would independently search their own way using their own keywords. Places of interest that have the potential to be the target were shared or/and discussed with other group members. Example responses included:

"Generally both people search for the same information (but with our own keywords) and then results are shared."

"No coordination. Everyone would search individually and whoever found a suitable result first would show it to the rest".

Different kinds of explicit coordination were reported in several responses to this question (21\%). This included dividing among participants local search tasks based on location, type of place, type of information, the Web service or application used for the search. For example:

"Occasionally, tasks were divided by geography or type (e.g. searching Italian and Greek restaurants separately, or looking up restaurants in Melbourne and Monash)".

"One would use Google, another would use Google Maps, another would use an App".

"place searched by one member and the location by other"

"The other group members used their smart phones to search the bus routes or tram timings" 
Several respondents (28\%) mentioned explicitly collaborating on another aspect of the search process that comes after the finding, which is making the choice of what would be their destination. That usually involves discussing the discovered places of interest, and group member may look for more information about these places. For example, two respondents stated:

"Once results were found, discussion then proceeded on what to do"

"The options were discussed - often more than one at a time. We would look at reviews and photos to find out more information"

\subsubsection{Experiences of collaborative searches operated by one person}

In order to understand how the other members participated when only one person operated the search, we asked: "Thinking of the occasions when only one group member used his/her mobile/non-mobile device to find a place of interest for the group, please describe how some or all of other group members participated on the search/browse?". The responses $(\mathrm{n}=25)$ fell into two main categories. In $56 \%$ of the answers, one or more group members were directly involved by trying to help the searcher, suggesting query terms, links to be followed, or Websites to be looked up:

"People will provide input on what terms to search, and what links to click on"

"Suggestions for search terms, narrowing down search options, describing advanced methods of finding information through google maps or other apps"

"Mainly just advising which sites to look at or search words to type in google"

Group members also contributed by suggesting areas or places to be searched:

"Other members tried to refine the address by suggesting neighboring locations"

"The other member(s) suggested locations and/or popular place names to start the search with"

In the second category of answers (44\%), group members reported discussing search results and participating in the process of deciding which place of interest to pick:

"Lots of pointing and comments like What about that one? or I've been there and it wasn't that great"

"They provided feedback and/or opinions regarding choosing the places of interest to visit"

\subsection{Difficulties in collaboration}

The next question asked: "Please describe any kind of inconvenience(s) experienced during the participation by two or more group members?".

Choosing or agreeing on a place of interest that suits all group members was the most frequently reported difficulty $(54 \%, n=24)$, examples included:

"People disagreed on what venue would be most suitable"

"Finding something that suited everybody, or at least that everybody was prepared to go along with" 
"Many people to satisfy (e.g. different criteria for a good hotel, or restaurant)"

Other inconveniences were the difficulty of communicating or sharing search results among group members. For example, one respondent wrote:

"When not face-to-face, it is difficult to share live results (as and when you come across a result). Calling up the other members or text messaging in bulk is inconvenient. Particularly when members suggest a slight modification to the search query, you have to redo the search, then call up again to report the new results with this slightest of change."

"hard to explain results"

The inconvenience of more than one person interacting with one mobile device, e.g.:

"Lots of people's input into one device with a small screen can slow progress"

"Inability of the group members to interact with the device (mobile phone) or even easily seeing the screen"

The problem of coordinating the search task among group members, e.g.:

"It's hard to coordinate searches"

"finding the same thing at the same time"

The issue of keeping track of results found by different group members. One response stated:

"There is no real good way to keep track of the different information being found by different people"

In addition, a few respondents reported problems related to mobile device usability, including poor network connection reliability, and difficulties with limited screen sizes.

\subsection{Decision Making}

Commonly, the place of interest being sought should be suitable for as many of the group as possible; a process that needs to be decided upon. In order to have an understanding of this aspect, we asked the following four questions

We asked: "How often did some or all of the group members have different opinions or preferences over the potential targeted places of interest?". The results $(n=59)$ indicated that the difference of opinions or preferences about places of interest among group members occurred quite frequently, with a quarter saying that it happened "Quite often", in addition to $47 \%$ who answered "Sometimes", while only one respondent answered that it "Never" happened.

Next, we asked: "How often was someone you do not know very well involved in the group?". That situation did not appear to be widespread, with $46 \%$ responses ( $n=59)$ saying it was rare, and $20 \%$ saying it never happened to them. However, 22\% had that experience "Sometimes", and 10\% "Quite Often". A Spearman rank-order correlation coefficient was computed to assess the relationship between the frequency of having different opinions or preferences and the involvement of someone not very well 
known to the other group members (Table 10 displays the relationship between both variables). There was a weak positive, but significant, correlation between the two variables, $r=0.3, p=0.0192$.

\begin{tabular}{|c|c|c|c|c|c|c|c|}
\hline & \multicolumn{5}{|c|}{ Involvement of someone not very well known to other group members } & \multirow[b]{2}{*}{ Total } \\
\hline & & Never & Rarely & Sometimes & Quite Often & Very Often & \\
\hline \multirow{6}{*}{ 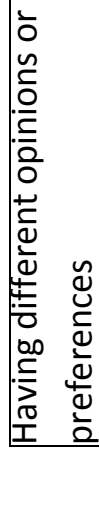 } & Never & 1 & 0 & 0 & 0 & 0 & 1 \\
\hline & Rarely & 5 & 5 & 2 & 0 & 0 & 12 \\
\hline & Sometimes & 4 & 14 & 6 & 3 & 1 & 28 \\
\hline & Quite Often & 2 & 6 & 5 & 2 & 0 & 15 \\
\hline & Very Often & 0 & 2 & 0 & 1 & 0 & 3 \\
\hline & Total & 12 & 27 & 13 & 6 & 1 & 59 \\
\hline
\end{tabular}

Table 10. A contingency table of frequencies showing the relationship between having different opinions or preferences and the involvement of someone not very well known to the other group members.

In the next question (free form), the participants were asked: "Please describe the method( $s$ ) that were used to agree on the selection of places of interest?". About half (47\%) mentioned how the final decision was made ( $\mathrm{n}=37)$. Taking a vote or choosing the most liked option was dominant, however, some indicated that the most influential member of the group was the main contributor to the final decision:

"The alpha type person of the group is often the most extroverted and thus generally gets the sale and everyone agrees"

Some respondents described what the group members did during the process of making the choice: $17 \%$ reported that the group members together compared the choices by discussing their advantages and disadvantages. For example:

"Each place's pros and cons are listed out. Discussion and debating among members is done in order to come to a final decision."

Additionally, 35\% described what was taken into account when forming the decision. About half of those (54\%) mentioned looking at publicly available reviews and ratings of places of interest on the Web. Also, $69 \%$ of them talked about considering certain features related to places of interest such as location, price, photos, and availability. Example responses include:

"Distance, price, and public reviews are all important influencers in the final decision."

"the rating of the places found as in highest rating or best comments was picked." 
Previous or known experiences about potential places of interest were also among the factors reported to have affected the group decision in $8 \%$ of the answers.

Finally, we asked: "Did you ever have a certain opinion or preference over a targeted place of interest, but did not express it to the others in the group? If yes, please indicate why." Here, $37 \%(\mathrm{n}=59)$ answered "Yes", with 17 explaining why. Most reasons indicated that the member was aware that the others had a preference/opinion and they were happy to silently compromise. Two respondents reported that they did not express their preferences/opinions because they had thought that they might not be of interest to the other(s).

Opposite to what we expected, we found (using Mann-Whitney U test) that participants who answered "No" reported a significantly higher frequency regarding the involvement of someone not very well known to the other group members than those who answered "Yes", $U=281, z=1.97, p=0.0488$. The mean ranks were 33.4 for "No" group and 24.3 for "Yes" group. This could mean our participants were less likely to express their opinions or preferences when they know all people involved in the group very well, but that needs to be studied further for clearer understanding.

\section{DISCUSSION}

In this section, we discuss what some of the results could potentially mean in terms of improving collaborative local search applications.

\subsection{Relevance of the cohort}

We first examine the cohort used in the questionnaire. We selected university computer science students in the hope that we would identify a group of early adopters of technology that would enable the results to generalize as use of technologies such as smartphones increases in the wider population.

The level of ownership of smartphones reported by our users, $81 \%$, was higher than smartphone adoption rates gathered in the same year as the survey was conducted. For example, a sales study over 12 weeks ending in March 2012 (Lunden, 2012), showed that 57\% of Australian mobile consumers own a smartphone. The cause of the students being early adopters is likely due to their interest in computer science, but also, partially, due to age. The two age groups with the highest rates of smartphone ownership were 18-24 and 25-34, 54\% and 62\% of mobile phone owners respectively, (Nielsen, 2011). At least $79 \%$ of our respondents belong to these two age groups. This suggests our choice of target group achieved one of our aims of finding high numbers of smartphone users. A recent study of local search usage found that $37 \%$ of online users search for local businesses at least once a week, while $21 \%$ had never performed this kind of search (ComScore, 2012). As seen in Table 3, 45\% of our respondents reported conducting local search at least once a week and only $6 \%$ had never conducted a local search. Although these figures may not be directly comparable (as the past study focused only on businesses), local search appeared to be more popular among our participants than that found in past work.

Additionally, users were asked if when searching for a place of interest for a group, the members of the group knew each other well. As reported in Section 4.5, the participants reported that groups tended to be composed of people who know each other well. Although not directly comparable, this finding appears to be in line with what was reported by Church et al. (2012), that group-based co-located mobile searches 
primarily involve people with close relationships, that is, friends, family, and partners or spouses. While they also occurred with work colleagues, other types of relationship were rare.

\subsection{Devices searched on}

The devices that were searched on was touched upon in the questionnaire. The results shown in Table 4 indicate that searches for places of interest were conducted on a range of devices, not just mobile phones. Recent research about local search has mainly focused on search tasks initiated from mobile devices, (for example, Amin et al., 2009; Lv, Lymberopoulos, \& Wu, 2012; Teevan et al., 2011) ignoring other types of networked computer. Some past research has examined both types of computer. The difference in the percentages of iPhone and computer local searches was found to be non-significant in a log-based analysis of Web search queries ${ }^{5}$ (Kamvar, Kellar, Patel, \& Xu, 2009). According to a study by ComScore (2012), frequencies of local search for businesses on computers and mobile phones were similar; however, $26 \%$ of smartphone users had never conducted a search on the device, compared to only $1 \%$ with regard to computer users. Moreover, only $29.6 \%$ of queries about restaurants going through Google are mobile (Spero, 2011).

In addition, it can be seen from Table 8, row 2 that mobiles were commonly used for collaborative search. At least one mobile device was used by almost half (48\%) of the respondents; only $6 \%$ never used a mobile device in collaborative search. Finding out that co-located collaboration was popular may give a hint about this; perhaps suggesting that when the participants are together, they are likely to be away from their desktop/laptop computers, searching on mobile devices. Teevan et al. (2011), just studying mobile devices reported that $66 \%$ of the searches performed in a car or bus were social, in contrast to $45 \%$ of those conducted at home.

As respondents reported both use of smartphone and desktop computers, potential improvements to the user experience could occur both in the searching system users access and in the devices users search on.

\subsection{What to search for}

The types of items searched for was also examined. As shown in Table 7, it was found that the most popular items were places to eat or drink (88\% of the 69 respondents), entertainment attractions (59\%), and places to shop (33\%). These figures contrast with the study from Teevan et al. on mobile local search that is not necessarily collaborative. She and her co-authors found that restaurants were what people were most likely to search for (48\% of queries), followed by stores (21\%) and attractions (10\%) (Teevan et al., 2011). In another study, (Amin et al., 2009), stores were the most popular (27\% of queries), followed by food \& drink (24.5\%), and entertainment (13.7\%). In comparison with these past results, finding places to shop seems to be less popular in collaborative search.

\subsection{Collaboration and co-location with others}

When considering collaboration, we first asked if users had been in a group when searching for a place of interest. We reported that the majority $(87 \%)$ of the respondents were involved in such a situation at least once. Teevan et al. (2011) showed, via a survey, that $63 \%$ of 929 mobile users discussed their last local

\footnotetext{
${ }^{5}$ This analysis was only about queries sent out from the Web browser. Thus, searches from mobile applications, e.g. maps, were not included.
} 
mobile search with someone, which implies that the information needs in these cases were group-based. Morris (2008) reported that $96.1 \%$ shared Web search products (e.g. useful links, facts extracted from sites) with others. It would appear that this social searching situation is common.

Results from the questionnaire indicated that being together (co-located) with other group members when finding a place of interest was more frequent than being apart. In Table 8 (row 1), 35\% of respondents reported being together in most of their collaborative local searches, and $16 \%$ were together in all of them. In contrast, that does not appear to be the case for general Web collaborative search. In $42 \%$ of the collaborative searches reviewed by Capra et al. (2011), the participants were in different locations, while in $38 \%$ of them they were co-located during the search.

The majority (78\%) of the respondents in our questionnaire reported that there was collaboration (by any means) in the search in at least one past search for a place of interest. Of the respondents who answered this question, $49 \%$ reported that half or more of the place of interest group-based searches involved collaboration. In Web search in general, Morris (2008) and Capra et al. (2011) showed that $90.2 \%$ and $96 \%$ of users had collaborated on search, respectively. So, a collaboration rate of $78 \%$ for places of interest search suggests that it is one of the main kinds of Web search tasks that people perform cooperatively.

Table 8, row 4 reports responses to questions about how often only a single person operated the search for a place of interest. Only 7\% of respondents reported that "All" searches were by just one person. By implication searches operated by two or more were common to most respondents. Church et al. (2012) reported that in mobile search instances carried out in the presence of others to satisfy a shared information need, typically one person would conduct the search. Toze et al. (2011) observed in a lab experiment that the task of finding was mostly performed by one group member, and rarely by a pair, though the other information tasks (e.g. generating the information need) were often performed collaboratively. From our results multi-user participation in the finding activity is more prominent in the search for places of interest specifically and more prominent than reported in past literature.

Past research indicated that many mobile location-based information needs are discussed with someone else (Amin et al., 2009; Teevan et al., 2011). However, the significance of the actual multi-party collaboration was not clear. We showed that most of the respondents had experienced such collaboration at least once in the past, and for about half of the respondents, it occurred in at least half of the groupbased searches for places of interest. Moreover, in many of these cases the search was operated by more than one member of the group; in other words, the other member(s) did not only participate by helping the searcher verbally; rather, they performed some search activities themselves.

The questionnaire also asked how many cooperated. In the table below, we merge Table 9 (reporting figures from the questionnaire) with past results. In contrast with our results, collaborations in general Web search were found to be mainly performed by two people (Amershi \& Morris, 2009; Capra et al., 2011; Morris, 2008). A few groups of three or four were sometimes found. The only past study that appears to match our findings is the work of Capra et al. The average number of collaborators that we found (2.9) is similar to theirs (3.0).

We believe that these findings need to be considered in the design of search engines and websites providing local services. Features for supporting collaboration for groups should be developed in the core 
search functionality as well as in the user interface. Web searches (on mobile or desktop) for places of interest related to a group of people were found to occur fairly frequently. Therefore, there is a potential that the support for collaboration could encourage more groups of people to cooperate on satisfying their shared location-based information needs, and more group members to be more actively engaged in the seeking process. Since our results showed the high prevalence of co-located collaboration and the use of mobile devices, often multiple devices, in many co-located searches, these settings should be particularly supported. For example, mobile technologies, such as Near Field Communication $\left(\mathrm{NFC}^{6}\right)$, can be utilized to allow co-located mobile users to share discovered places of interest with each other. Recently, Teevan et al proposed that phone orientation could be used as a way to indicate that users wish to share their results and ratings. User studies from this initial work indicate that determining the best way to allow users to quickly, easily, and securely share are not yet determined. However, the researchers recommend designing for sharing in collaborative mobile search applications (Teevan, Morris, \& Azenkot, 2014).

\begin{tabular}{|l|r|r|r|r|}
\hline & 2 & 3 & 4 & $\geq 5$ \\
\hline Our study & $45 \%$ & $37 \%$ & $9 \%$ & $8 \%$ \\
\hline (M. R. Morris, 2008) & $80.7 \%$ & $19.3 \%$ & - \\
\hline (Amershi \& Morris, 2009) & $\begin{array}{r}\text { (work) } 85.7 \% \\
\text { (home) } 70.6 \%\end{array}$ & $\begin{array}{r}\text { (work) } 9.5 \% \\
\text { (home) } 29.4 \%\end{array}$ & - \\
\hline (Capra et al., 2011) & $58 \%$ & $20 \%$ & $14 \%$ & $8 \%$ \\
\hline
\end{tabular}

Table 11. Comparing results from our study (taken from Table 9) with results from past papers on general collaborative Web search.

\subsection{Coordination/division of labor}

Morris (2008) found that when explicit coordination was used, collaborators divide the search work by distributing different search engines or reference sites to group members, dividing up different search keywords among collaborators, or splitting up the search task into subtasks and allocating one for each group member. However for location-based search, our participants reported coordinating by dividing the search based on geography, place of interest type, or the search for a place of interest and the directions to get into it.

The results of our questionnaire indicated that respondents were not aware of coordination among collaborators in most cases. That could be due to the lack of features to facilitate coordination in current systems. The absence of coordination may lead to efforts of different group members being duplicated, which was reported as an inconvenience by some respondents; hence, offering features to support coordination is likely to be useful for collaborators. Perhaps on some occasions the group members may be keen to look at as many listed places in a given area as possible. A feature that assists participants to, for instance, effectively divide the targeted area amongst them can be especially helpful in such cases.

There is limited work in the area of supporting coordination for collaborative search. One example is SearchTogether (M. R. Morris \& Horvitz, 2007), where an automatic system that splits search results for

\footnotetext{
${ }^{6} \mathrm{http}: / /$ nfc-forum.org/
} 
users was tried. However, this particular approach for generic web search was found to be unpopular. To the best of our knowledge there has been no research on coordination for local search. There are different ways in which coordination could be tried. For example, some of our respondents reported dividing the search space based on geography, place of interest type, or the search for a place of interest and the directions to get into it. Additionally, more lightweight solutions can also be adopted. For instance, results already viewed and/or shared by a group member can be marked differently, when they appear among the results other participants are getting.

The participants' reporting about their collaborative search experience suggests that the collaboration effort was focused on finding places and discussing them rather than planning the search and coordinating the effort. That appears to be different from what was reported before about the participation levels of individuals within group activities, in which the participation was higher in the early stages of the information seeking process than in the later stages that involve the actual finding of relevant items (Toze et al., 2011). So it could be argued that various factors, such as the type of information need, have effect on how the collaboration unfolds over the different stages of the information seeking process, including the participation levels by the group members.

One of the concepts in human computer-interaction (HCI) is "the use of video game elements in nongaming systems", or what is known as gamification, to improve the experience and engagement of users (Deterding, Sicart, Nacke, O'Hara, \& Dixon, 2011). For example, users are given rewards (e.g. points, badges, levels, etc.) based on certain achievements. Our findings reinforce what has been found earlier that collaborators may compete with each other during the finding process (M. R. Morris, 2008; Twidale et al., 1997). Five participants in our survey mentioned competing in speed. For example, one of them gave the following description:

"...with everyone trying to get the answer quickly and it became less about finding the answer and more about seeing which one of us can get to the answer the quickest."

A possible strategy to get participants more engaged is by adding a layer of reward to search applications supporting multi-user collaboration.

\subsection{Sharing}

It was shown in previous research that sharing a search result or status with other participants is a major part of the collaboration process that users want better support for (M. R. Morris, 2008; Reis, Church, \& Oliver, 2012). The results of our survey showed that in the context of local search, sharing was also awkward. Our participants pointed out a specific situation where this issue can be particularly frustrating: the difficulty of interacting with the small screen of a mobile device by multiple co-located people. Moreover, when the search is operated by only one group member, our respondents described that other members participated in guiding the search and discussing potential places of interest. Therefore, an important aspect of sharing is making group members - including those who did not control the search more engaged.

Sharing results can be particularly important in local search, as results often involve visual information like maps and photos that are not easy to verbally describe. A few research systems have attempted to improve sharing in web search, by allowing collaborators to share search results and queries through the search interface itself (M. R. Morris \& Horvitz, 2007; Shah, 2010). For local search, almost all Web and 
mobile applications utilize web mapping services. Providing a shared map view that marks places found by collaborators would help all gain an overview of how the search is progressing. Doing so may also contribute to addressing another reported difficulty, which is keeping track of places shared by different people. In the case of co-located cooperative mobile local search, such a feature was experimented by Ashikaga, Iwata, Komaki, Hara, \& Nishio, (2011), and was found to be an effective way to share places. However, it would also be useful to have similar support for other collaboration settings, e.g. remote collaboration, other types of devices, e.g. PCs, and other search-related information, e.g. queries.

\subsection{Choosing the place of interest to go to}

In Section 4.3.4, many participants (44\%) reported discussing search results and participating in the process of deciding which place of interest to pick even if they weren't directly involved in searching. Our respondents also reported, that group members contributed to making the decision about choosing a place of interest by actively discussing the results and sharing opinions and experiences about them. Typically, group members would discuss places of interest that looked interesting to them. We showed that activities such as comparing the pros and cons and looking at related information, such as ratings and reviews, were among the main approaches the group members did to help in forming their group-based decision.

Agreeing on which place of interest to pick after searching was the most frequent inconvenience our respondents reported having. That was further supported by the finding that differences of opinion or preference are frequent among groups looking for places of interest. Additionally, we found that there is a slight increase in such differences when some in the group do not know each other very well. This finding requires further investigation. There is little past work that we could find on this aspect of collaborative search.

Possible means of helping groups more effectively decide on a single place of interest include better sharing of such information to facilitate easy comparison as well as providing a means to discuss results (particularly if collaborators are cooperating remotely). Taking a vote or choosing the most liked option appeared to be the main way for making the final choice, although the decision being influenced by one member was reported. Here, of value would be a mechanism to help group members voice their opinion particularly when there is no close relationship between the group, or when some participants are hesitant to reveal their actual opinions. The exact means by which this should be implemented requires further research.

We believe our survey's findings support the notion that a combination of mechanisms for effective sharing of search findings, comparison of results, communication, and expression of opinion could enhance the collaboration experience in local search.

Additionally, as the group decision was found to be an essential part of the collaboration, studying the information seeking processes (ISP) within the context of collaboration on local search is probably needed to understand how the group decision develops over the process, and what it is affected by. For example, some studies, such as (Hyldegård, 2006; Shah \& González-Ibáñez, 2010), have looked at the positive and negative feelings of collaborators during the different stages of the information seeking process. Investigating that aspect and its effect on the group decision in local search would provide more insight into that issue and how it can be effectively supported. 


\section{CONCLUSIONS}

In this paper we presented the results of a survey investigating collaborative behaviors surrounding groupbased search for places of interest. Although some recent research has highlighted the link between local search and group activities, the work presented here is, to the best of our knowledge, the first to exclusively explore multi-user collaboration in local search. The work investigated the following research questions:

- How often do group-based searches for places of interest occur? In how many of these searches is there actual collaboration among some or all of the group?

- What are the details of the collaboration? What are the common targeted places of interest, how are mobile devices used, who is controlling the search, what size of group is involved, are the group members co-located or remote, and how does the collaboration takes place?

- What, if any, are the obstacles faced during the collaboration?

- How important is the process of deciding which place of interest will be chosen? And how is that decision made?

Searches for places of interest related to a group of people were found to be relatively frequent, and about half of these searches involved active participation by more than one group member. The use of smartphones to carry out the cooperative search was dominant, as well as co-located collaboration, which in many cases involved the use of multiple phones. A large proportion of the local collaborative searches were operated by more than one person.

Places to eat or drink were the most common destinations searched collaboratively, followed by places to shop. Most commonly, two people carried out the search, but collaborations involving three people were also quite common. Collaboration was mostly uncoordinated, although dividing the local search tasks based on different dimensions was reported. Participants who did not operate the search were often actively involved suggesting areas to be searched, discussing the results, or making the choice.

Deciding a place of interest that suited all people involved was found to be the most common issue people experience during the collaboration. That was backed by finding that group members commonly have different opinions or preferences over potential places of interest. Decisions were normally made based on which place of interest was the most voted for by the participants, although the decision being mainly made by one influential person was also described.

Current Web services and interfaces for finding places of interest are mainly designed for single users. We hope that these findings can encourage and inform the development of features that help groups of people to cooperatively find and choose places of interest that suit their shared needs. In terms of future work of this research, we are planning to study the collaboration on places of interest search in more detail through an observational study. We are also going to implement and evaluate an interface for supporting group-based search of and decisions on places of interest. 


\section{REFERENCES}

Amershi, S., \& Morris, M. R. (2008). CoSearch: a system for colocated collaborative web search. In Proceeding of ACM SIGCHI (pp. 1647-1656).

Amershi, S., \& Morris, M. R. (2009). Co-located collaborative web search: understanding status quo practices. In CHI '09 Extended Abstracts on Human Factors in Computing Systems (pp. 36373642). New York, NY, USA: ACM. doi:10.1145/1520340.1520547

Amin, A., Townsend, S., van Ossenbruggen, J., \& Hardman, L. (2009). Fancy a Drink in Canary Wharf?: A User Study on Location-Based Mobile Search. In T. Gross, J. Gulliksen, P. Kotzé, L. Oestreicher, P. Palanque, R. Prates, \& M. Winckler (Eds.), Human-Computer Interaction - INTERACT 2009 (Vol. 5726, pp. 736-749). Springer Berlin / Heidelberg. Retrieved from http://dx.doi.org/10.1007/978-3-642-03655-2_80

Ashikaga, E., Iwata, M., Komaki, D., Hara, T., \& Nishio, S. (2011). Exploring map-based interactions for co-located collaborative work by multiple mobile users. In Proceedings of the 19th ACM SIGSPATIAL International Conference on Advances in Geographic Information Systems (pp. 417420). New York, NY, USA: ACM. doi:10.1145/2093973.2094037

Capra, R., Chen, A. T., Hawthorne, K., Arguello, J., Shaw, L., \& Marchionini, G. (2012). Design and evaluation of a system to support collaborative search. Proceedings of the American Society for Information Science and Technology, 49(1), 1-10. doi:10.1002/meet.14504901181

Capra, R., Marchionini, G., Velasco-Martin, J., \& Muller, K. (2010). Tools-at-hand and learning in multisession, collaborative search. In Proceedings of the 28th international conference on Human factors in computing systems (pp. 951-960). New York, NY, USA: ACM. doi:10.1145/1753326.1753468

Capra, R., Velasco-Martin, J., \& Sams, B. (2011). Collaborative information seeking by the numbers. In Proceedings of the 3rd international workshop on Collaborative information retrieval (pp. 7-10). New York, NY, USA: ACM. doi:10.1145/2064075.2064078

Church, K., Cousin, A., \& Oliver, N. (2012). I wanted to settle a bet!: understanding why and how people use mobile search in social settings. In Proceedings of the 14th international conference on Humancomputer interaction with mobile devices and services (pp. 393-402). New York, NY, USA: ACM. doi:10.1145/2371574.2371635

Church, K., \& Oliver, N. (2011). Understanding mobile web and mobile search use in today's dynamic mobile landscape. In Proceedings of the 13th International Conference on Human Computer Interaction with Mobile Devices and Services (pp. 67-76). New York, NY, USA: ACM. doi:10.1145/2037373.2037385

Church, K., \& Smyth, B. (2009). Understanding the intent behind mobile information needs. In Proceedings of the 14th international conference on Intelligent user interfaces (pp. 247-256). New York, NY, USA: ACM. doi:10.1145/1502650.1502686

ComScore. (2012). 5th Annual 15miles/Localeze Local Search Usage Study. Retrieved from http://goo.gl/x6Lwd

DeSanctis, G., \& Gallupe, B. (1984). Group decision support systems: a new frontier. SIGMIS Database, 16(2), 3-10. doi:10.1145/1040688.1040689

Deterding, S., Sicart, M., Nacke, L., O'Hara, K., \& Dixon, D. (2011). Gamification. using game-design elements in non-gaming contexts. Proceedings of the 2011 Annual Conference Extended Abstracts on Human Factors in Computing Systems - CHI EA '11, 2425. doi:10.1145/1979742.1979575 
Evans, B. M., \& Chi, E. H. (2008). Towards a model of understanding social search. In Proceedings of the 2008 ACM conference on Computer supported cooperative work (pp. 485-494). ACM. Retrieved from http://dl.acm.org.ezproxy.lib.rmit.edu.au/citation.cfm?id=1460641

Gan, Q., Attenberg, J., Markowetz, A., \& Suel, T. (2008). Analysis of geographic queries in a search engine log. In Proceedings of the first international workshop on Location and the web (pp. 49-56). New York, NY, USA: ACM. doi:10.1145/1367798.1367806

González-ibáñez, R. (2011). Evaluating the Synergic Effect of Collaboration in Information Seeking. Information Storage and Retrieval.

Hansen, P., \& Järvelin, K. (2005). Collaborative Information Retrieval in an information-intensive domain. Information Processing \& Management, 41(5), 1101-1119. doi:10.1016/j.ipm.2004.04.016

Hyldegård, J. (2006). Collaborative information behaviour-exploring Kuhlthau's Information Search Process model in a group-based educational setting. Information Processing \& Management, 42(1), 276-298. doi:10.1016/j.ipm.2004.06.013

Kamvar, M., \& Baluja, S. (2006). A large scale study of wireless search behavior: Google mobile search. In Proceedings of the SIGCHI conference on Human Factors in computing systems (pp. 701-709). New York, NY, USA: ACM. doi:10.1145/1124772.1124877

Kamvar, M., Kellar, M., Patel, R., \& Xu, Y. (2009). Computers and iphones and mobile phones, oh my!: a logs-based comparison of search users on different devices. In Proceedings of the 18th international conference on World wide web (pp. 801-810). New York, NY, USA: ACM. doi:10.1145/1526709.1526817

Kasunic, M. (2005). Designing an effective survey.

Large, A., Beheshti, J., \& Rahman, T. (2002). Gender differences in collaborative web searching behavior: an elementary school study. Information Processing \& Management, 38(3), 427-443.

Lazar, J., Feng, J. H., \& Hochheiser, H. (2010). Research methods in human-computer interaction. Wiley.

Lunden, I. (2012). Kantar Worldpanel: Android Dominates Smartphone Sales Overall; In U.S. iOS Closing In. TechCrunch. Retrieved from http://goo.gl/fAf9C

Lv, Y., Lymberopoulos, D., \& Wu, Q. (2012). An exploration of ranking heuristics in mobile local search. In Proceedings of the 35th international ACM SIGIR conference on Research and development in information retrieval (pp. 295-304). New York, NY, USA: ACM. doi: $10.1145 / 2348283.2348325$

Metts, S., Sprecher, S., Cupach, W. R., Montgomery, B. M., \& Duck, S. (1991). Retrospective selfreports. Studying Interpersonal Interaction, 162-178.

Morris, M. R. (2008). A survey of collaborative web search practices. In Proceeding of the twenty-sixth annual CHI conference on Human factors in computing systems - CHI '08 (pp. 1657-1660). New York, New York, USA: ACM Press. doi:10.1145/1357054.1357312

Morris, M. R., \& Horvitz, E. (2007). SearchTogether. In Proceedings of the 20th annual ACM symposium on User interface software and technology - UIST '07 (p. 3). New York, New York, USA: ACM Press. doi:10.1145/1294211.1294215

Morris, M. R. M. (2013). Collaborative search revisited. In Proceedings of the 2013 conference on Computer supported cooperative work (pp. 1181-1192). New York, NY, USA: ACM. doi:10.1145/2441776.2441910

Nielsen. (2011). GENERATION APP 62\% OF MOBILE USERS 25-34 OWN SMARTPHONES. Retrieved from http://goo.gl/MSAlq 
Poltrock, S., Grudin, J., Dumais, S., Fidel, R., Bruce, H., \& Pejtersen, A. M. (2003). Information seeking and sharing in design teams. In Proceedings of the 2003 international ACM SIGGROUP conference on Supporting group work (pp. 239-247). New York, NY, USA: ACM. doi:10.1145/958160.958198

Power, D. J. (2004). Decision Support Systems: Frequently Asked Questions. iUniverse.

Reis, S., Church, K., \& Oliver, N. (2012). Rethinking mobile search: towards casual, shared, social mobile search experiences. In Proceedings of the "Searching 4 Fun!" workshop, collocated with ECIR 2012 (pp. 1-4). Barcelona, Spain: CEUR-WS. Retrieved from http://ceur-ws.org/Vol836/paper1.pdf

Saleh, N., \& Large, A. (2011). Collaborative information behaviour in undergraduate group projects: A study of engineering students. Proceedings of the American Society for Information Science and Technology, 48(1), 1-10. doi:10.1002/meet.2011.14504801035

Shah, C. (2010). Coagmento- A Collaborative Information Seeking, Synthesis and Sense-Making Framework (an integrated demo). In Proceedings of Computer Supported Cooperative Work CSCW.

Shah, C. (2013). Effects of awareness on coordination in collaborative information seeking. Journal of the American Society for Information Science and Technology, 64(6), 1122-1143. doi:10.1002/asi.22819

Shah, C., \& González-Ibáñez, R. (2010). Exploring information seeking processes in collaborative search tasks. Proceedings of the American Society for Information Science and Technology, 47(1), 1-7. doi:10.1002/meet.14504701211

Sohn, T., Li, K. A., Griswold, W. G., \& Hollan, J. D. (2008). A diary study of mobile information needs. Proceeding of the Twentysixth Annual CHI Conference on Human Factors in Computing Systems CHI 08, 433. doi:10.1145/1357054.1357125

Spero, J. (2011). The Time for Mobile is now. Retrieved from http://goo.gl/VBQvY

Talja, S. (2002). Information sharing in academic communities: Types and levels of collaboration in information seeking and use, 143-159. Retrieved from http://www.uta.fi/ lisaka/Taljaisic2002_konv.pdf

Teevan, J., Karlson, A., Amini, S., Brush, A. J. B., \& Krumm, J. (2011). Understanding the importance of location, time, and people in mobile local search behavior. In Proceedings of the 13th International Conference on Human Computer Interaction with Mobile Devices and Services (pp. 77-80). New York, NY, USA: ACM. doi:10.1145/2037373.2037386

Teevan, J., Morris, M., \& Azenkot, S. (2014). Using Physical Signaling to Support Collaborative Mobile Search. In Proceedings of the Companion Publication of the 17th ACM Conference on Computer Supported Cooperative Work \&\#38; Social Computing (pp. 245-248). New York, NY, USA: ACM. doi:10.1145/2556420.2556493

Toze, S. L., McCay Peet, L., \& Toms, E. G. (2011). Group participation in the search process? In Collaboration Technologies and Systems (CTS), 2011 International Conference on (pp. 69-76).

Twidale, M. B., Nichols, D. M., \& Paice, C. D. (1997). Browsing is a collaborative process. Information Processing \& Management, 33(6), 761-783.

Yi, J., Maghoul, F., \& Pedersen, J. (2008). Deciphering mobile search patterns: a study of Yahoo! mobile search queries. In Proceedings of the 17th international conference on World Wide Web (pp. 257266). New York, NY, USA: ACM. doi:10.1145/1367497.1367533 


\section{Appendix A. The Number of Responses for Each Question}

The following table lists the survey questions and number of responses for each one.

\begin{tabular}{|c|c|}
\hline Are you male or female? & 100 \\
\hline Which category below includes your age? & 100 \\
\hline What is the highest level of school you have completed or the highest degree you have received? & 100 \\
\hline Do you use a smart-phone (ex. an iPhone, Android, or Windows mobile device)? & 100 \\
\hline $\begin{array}{l}\text { How often did you use the Web to find a suitable place of interest (a restaurant, hotel, shop, } \\
\text { entertainment attraction, natural attraction, etc.)? (Through a mobile or non-mobile device). }\end{array}$ & 98 \\
\hline $\begin{array}{l}\text { Thinking of these occasions when you used the Web to find a place of interest, how many of these } \\
\text { occasions was a mobile device used in the search/browse? }\end{array}$ & 89 \\
\hline $\begin{array}{l}\text { How often were you part of a group (two or more people) in which the Web was used to find a } \\
\text { suitable place of interest for the group? (Whether the search was done by yourself or/and others in } \\
\text { the group, through a mobile or non-mobile device). }\end{array}$ & 95 \\
\hline $\begin{array}{l}\text { Thinking of these occasions when the Web was used to find a place of interest for the group, how } \\
\text { many of these occasions did more than one member of the group participate (by any form) in the } \\
\text { search/browse? (Whether the participation was by actually doing a search/browse on a mobile/non- } \\
\text { mobile device, or by trying to help someone in the group who is doing that). }\end{array}$ & 82 \\
\hline In these occasions, what were the most common (up to 3 ) targeted places of interest? & 69 \\
\hline $\begin{array}{l}\text { How often of these occasions were group members together (face-to-face) when participating on the } \\
\text { search/browse for a place of interest? }\end{array}$ & 69 \\
\hline $\begin{array}{l}\text { How often of these occasions was at least one mobile device used to find a place of interest for the } \\
\text { group? }\end{array}$ & 69 \\
\hline $\begin{array}{l}\text { How often of these occasions was the actual search/browse for a place of interest done by only one } \\
\text { group member, while some or all of other group members participated by trying to help him/her on } \\
\text { the search/browse? }\end{array}$ & 69 \\
\hline Typically, how many group members participated on the search/browse for places of interest? & 69 \\
\hline $\begin{array}{l}\text { Thinking of these occasions when the group members were together (face-to-face) when participating } \\
\text { on finding a place of interest, how many of these occasions did two or more group members use their } \\
\text { mobile devices to participate on the search/browse? }\end{array}$ & 47 \\
\hline $\begin{array}{l}\text { Thinking of the occasions when two or more group members used their mobile/non-mobile devices to } \\
\text { participate on finding places of interest, please describe how the collaboration occurred. (Ex. in terms } \\
\text { of dividing/coordinating tasks, sharing results, etc.) }\end{array}$ & 29 \\
\hline $\begin{array}{l}\text { Thinking of the occasions when only one group member used his/her mobile/non-mobile device to } \\
\text { find a place of interest for the group, please describe how some or all of other group members } \\
\text { participated on the search/browse? }\end{array}$ & 25 \\
\hline $\begin{array}{l}\text { Please describe any kind of inconvenience(s) experienced during the participation by two or more } \\
\text { group members? }\end{array}$ & 24 \\
\hline $\begin{array}{l}\text { How often did some or all of the group members have different opinions or preferences over the } \\
\text { potential targeted places of interest? }\end{array}$ & 59 \\
\hline How often was someone you do not know very well involved in the group? & 59 \\
\hline Please describe the method(s) that were used to agree on the selection of places of interest? & 37 \\
\hline $\begin{array}{l}\text { Did you ever have a certain opinion or preference over a targeted place of interest, but did not express } \\
\text { it to the others in the group? }\end{array}$ & 59 \\
\hline If yes, please indicate why. & 17 \\
\hline
\end{tabular}

Table 12. The number of respondents for each of the survey questions. 